\title{
Integrating field and satellite data for spatially explicit inference on the density of threatened arboreal primates
}

\author{
Nathalie Cavada,,${ }^{1,2,7}$ Marco Ciolli, ${ }^{1}$ Duccio Rocchini, ${ }^{3}$ Claudia Barelli, ${ }^{2}$ \\ Andrew R. Marshall, ${ }^{4,5}$ and Francesco Rovero 2,6 \\ ${ }^{1}$ DICAM Department of Civil, Environmental and Mechanical Engineering, University of Trento, \\ Via Mesiano 77, 38123 Trento, Italy \\ ${ }^{2}$ Tropical Biodiversity Section, MUSE-Museo delle Scienze, Corso del Lavoro e della Scienza 3, 38122 Trento, Italy \\ ${ }^{3}$ Biodiversity and Molecular Ecology Department, Research and Innovation Centre-Fondazione Edmund Mach, \\ via E. Mach 1, 38010 San Michele all' Adige, Italy \\ ${ }^{4}$ CIRCLE, Environment Department, University of York, York YO10 5DD, United Kingdom \\ ${ }^{5}$ Flamingo Land Ltd., Kirby Misperton, North Yorkshire, York YO17 6UX, United Kingdom \\ ${ }^{6}$ Udzungwa Ecological Monitoring Centre, Udzungwa Mountains National Park, Mang'ula, Tanzania
}

\begin{abstract}
Spatially explicit models of animal abundance are a critical tool to inform conservation planning and management. However, they require the availability of spatially diffuse environmental predictors of abundance, which may be challenging, especially in complex and heterogeneous habitats. This is particularly the case for tropical mammals, such as nonhuman primates, that depend on multi-layered and species-rich tree canopy coverage, which is usually measured through a limited sample of ground plots. We developed an approach that calibrates remote-sensing imagery to ground measurements of tree density to derive basal area, in turn used as a predictor of primate density based on published models. We applied generalized linear models (GLM) to relate 9.8-ha ground samples of tree basal area to various metrics extracted from Landsat 8 imagery. We tested the potential of this approach for spatial inference of animal density by comparing the density predictions for an endangered colobus monkey, to previous estimates from field transect counts, measured basal area, and other predictors of abundance. The best GLM had high accuracy and showed no significant difference between predicted and observed values of basal area. Our species distribution model yielded predicted primate densities that matched those based on field measurements. Results show the potential of using open-access and global remote-sensing data to derive an important predictor of animal abundance in tropical forests and in turn to make spatially explicit inference on animal density. This approach has important, inherent applications as it greatly magnifies the relevance of abundance modeling for informing conservation. This is especially true for threatened species living in heterogeneous habitats where spatial patterns of abundance, in relation to habitat and/or human disturbance factors, are often complex and, management decisions, such as improving forest protection, may need to be focused on priority areas.
\end{abstract}

Key words: abundance; basal area; GIS; Landsat; primates; remote sensing; spatially explicit models; tropical forest; Udzungwa.

\section{INTRODUCTION}

Species abundance estimation and the identification of factors predicting its variation is a pervasive goal in ecology and conservation biology and it is gaining increasing attention through the emergent potential of spatially explicit modeling (Guisan and Zimmermann 2000, Guisan and Thuiller 2005, Wulder and Franklin 2006, Anadón et al. 2010). This is particularly true for threatened species living in heterogeneous landscapes, where habitat structure and human disturbance vary according to complex spatial patterns. In these contexts, inference on abundance becomes truly informative

Manuscript received 7 April 2016; revised 20 July 2016; accepted 1 August 2016. Corresponding Editor: Willem J. D. van Leeuwen.

${ }^{7}$ E-mail: nathalie.cavada@unitn.it only when it accounts for such heterogeneity (ArroyoRodríguez and Fahrig 2014). Human-modified landscapes are also expanding in tropical areas, where forest fragmentation, degradation, and defaunation strongly affect species viability (Balmford and Whitten 2003, Arroyo-Rodríguez and Fahrig 2014). However, because of limited and substandard data, spatially explicit models are less exploited in tropical areas compared to temperate ones (Cayuela et al. 2009). Thus, integrating the use of field data with remote-sensing data represents an advantageous approach to ensure data quality for spatial modeling in these areas (Wilkie and Finn 1996, Proisy et al. 2007).

Remote-sensing data (especially Landsat) have been used to investigate several ecological questions, mainly related to land cover change, carbon storage, and habitat mapping (Schroeder et al. 2011, Legaard et al. 2015, 
Mayes et al. 2015, Twongyirwe et al. 2015). However, the resolution and quality of Landsat data do not always adequately represent environmental components that are most important for target species, such as vegetation structure, because optical satellite imagery is not threedimensional (Hall et al. 1995, Duncanson et al. 2010). Therefore, methods are needed to characterize features of the forest structure that are relevant to target species, particularly for inaccessible areas where Landsat images represent the only feasible option.

In this study, we aimed to derive arboreal primate density from remote-sensing estimates of "tree stem basal area." Basal area is typically related to canopy cover (Alexander 1971, Farr et al. 1989, Smith et al. 1992), but the two measures are not directly interchangeable (Cade 1997). In particular, mean basal area specifically measures the contribution of each tree to biomass and hence identifies forest structure, succession stage, and disturbance. Accordingly, it is a common measure of habitat quality for predicting animal abundance (Braithwaite et al. 1989, Medley 1993, Umapathy and Kumar 2000). This is especially true for nonhuman primates (Mbora and Meikle 2004, Cristóbal-Azkarate et al. 2005, Anderson et al. 2007, Struhsaker and Rovero 2007), which are globally threatened and in urgent need of conservation actions (Schipper et al. 2008, Schwitzer et al. 2015). Our specific objectives were to (1) model measured basal area against a combination of different metrics and indices derived from Landsat imagery; (2) test the performance of the bestperforming model to predict values of basal area outside of the sampled areas; (3) use the results to derive a spatial map of population density of the endangered (IUCN 2015) Udzungwa red colobus monkey (Procolobus gordonorum), based on previously published density-basal-area model; (4) compare the modeled primate density to previous predictions from field measurements; (5) further refine these estimates using environmental and human predictors.

\section{Materials And Methods}

\section{Study area}

The Udzungwa Mountains are located in the southcentral part of Tanzania and represent the largest mountain bloc in the Eastern Arc Mountains, covering an area larger than $19000 \mathrm{~km}^{2}$ (Platts et al. 2011). Closed forest blocs, ranging in size from 12 to $>500 \mathrm{~km}^{2}$ (Marshall et al. 2010), are interspersed with drier habitats. We focused our study on the forest of Mwanihana, one of the largest forest blocs $\left(150.6 \mathrm{~km}^{2}\right)$ and under the protection of the Udzungwa Mountain National Park (UMNP) since 1992. Highly variable habitat types are distributed along the altitudinal gradient of the forest ranging from 351 to $2263 \mathrm{~m}$ above sea level. Deciduous forest is found in the lowland, with semideciduous and evergreen forests covering the sub-montane and montane areas, while Hagenia and bamboo-dominated forest characterize the upper montane level (Lovett et al. 2006). Woody vegetation density increases with elevation,

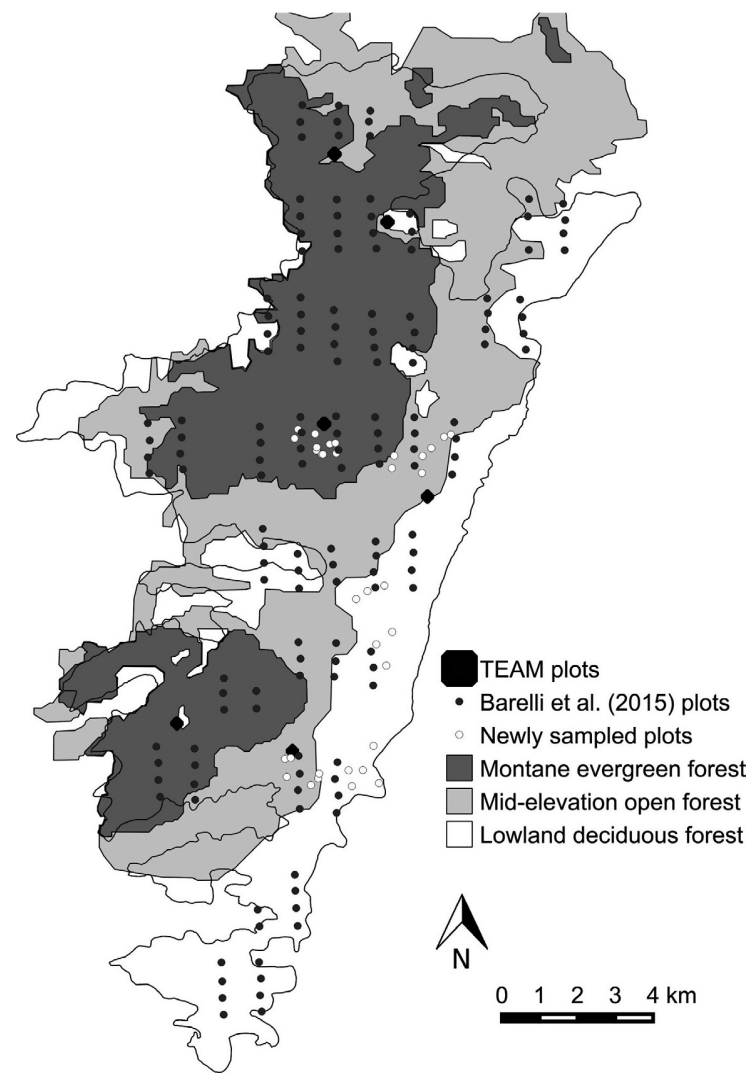

FIg. 1. Map of Mwanihana forest in the Udzungwa Mountains of Tanzania showing the distribution of three vegetation plots data sets used to derive basal area.

with the largest trees found at mid elevation, probably a result of human disturbance and tree respiration costs (Marshall et al. 2012).

\section{Vegetation data}

We derived field data for tree stems $\geq 10 \mathrm{~cm} \mathrm{DBH}$ (diameter at breast height; $1.3 \mathrm{~m}$ above the ground) from three sources (Fig. 1): (1) From the Tropical Ecology Assessment and Monitoring Network (TEAM; data set ID 03270119054443$),{ }^{8}$ comprising six vegetation plots of $100 \times 100 \mathrm{~m}$ on a horizontal plane (i.e., adjusted for slope), following a standardized protocol (TEAM Network 2011); (2) 153 vegetation plots of $25 \times 25 \mathrm{~m}$, sampled along line transects uniformly distributed in the forest (from Barelli et al. 2015); (3) 33 new randomly placed vegetation plots of $25 \times 25 \mathrm{~m}$, sampled in JuneJuly 2015, stratified according to the predominant habitat gradient from disturbed lowland deciduous to mature montane evergreen forest. All newly sampled plots were placed in the center of Landsat pixels for concordance with our remote-sensing imagery. A summary of the vegetation data sets is provided in Data S1.

\footnotetext{
${ }^{8}$ http://www.teamnetwork.org/
} 
We obtained a single, cloud-free, L8 OLI/TIRS Landsat image (Landsat scene ID LC81670652014299LG N00, courtesy of the U.S. Geological Survey), acquired 26 October 2014.

\section{Primate density data}

Density data on the Udzungwa red colobus from across the study area were obtained from an earlier study (Cavada et al. 2016). This study used environmental covariates from the 153 plots established by Barelli et al. (2015) and distance sampling along line transects (Araldi et al. 2014), to estimate colobus density across the study area. Transect data were modeled as a hierarchical coupled logistic regression, assuming a Poisson distribution for the animal abundance at a transect level. The detection process of the distance sampling was modeled according to a multinomial distribution, assuming a monotonical decrease of the detection probability with the increasing distance of the animal groups from the observer. The influence of a series of environmental and human disturbance covariates was evaluated and incorporated on both the abundance and detection steps in the model. Final density estimates at the plot level were derived from environmental correlates that included mean basal area, elevation and distance from disturbance (i.e., forest edge), that were found to significantly affect the abundance and detectability of the red colobus in the study area.

\section{Analysis}

Landsat metrics and vegetation indices. - To model basal area we first derived various Landsat metrics (Table 1). This began with a principal component analysis (PCA) to extract uncorrelated information from the different spectral bands provided by the Operational Land Imager (OLI) sensor of the Landsat 8 satellite. After applying PCA, we further compressed the spectral data applying the tasseled cap transformation (TCT) to represent forest structure (Cohen et al. 1995). We also used a GRASS module (Neteler et al. 2012), modified to derive vegetation-related spectral indices, combining specific bands of the Landsat 8 satellite images (Data S2). Such indices enhance the signal related to vegetation, while minimizing background edaphic, solar and atmospheric effects (Jackson and Huete 1991).

TABLE 1. Vegetation indices extracted from a Landsat 8 image for comparison to ground-sampled measures of mean basal area (MBA).

\begin{tabular}{|c|c|c|c|}
\hline Index & Algorithm & Description & References \\
\hline Simple ratio $(\mathrm{SR})$ & $\mathrm{SR}=\rho_{\text {nir }} / \rho_{\text {red }}$ & $\begin{array}{l}\text { index related to changes in the amount of } \\
\text { green vegetation; reduces the effect of } \\
\text { atmosphere and topography }\end{array}$ & Jordan (1969) \\
\hline $\begin{array}{l}\text { Corrected simple ratio } \\
\text { (SRC) }\end{array}$ & $\begin{aligned} \mathrm{SRC} & =\mathrm{SR}\left(1-\left(\left(\rho_{\operatorname{mir}}\right.\right.\right. \\
& \left.-\rho_{\operatorname{mir} \min }\right) /\left(\rho_{\operatorname{mir} \max }\right. \\
& \left.\left.-\rho_{\operatorname{mirmin}}\right)\right)\end{aligned}$ & $\begin{array}{l}\text { linearizes the relationships with } \\
\text { parameters, accounting for MIR band }\end{array}$ & $\begin{array}{l}\text { Brown et al. } \\
\quad(2000)\end{array}$ \\
\hline $\begin{array}{l}\text { Normalized difference } \\
\text { vegetation index } \\
\text { (NDVI) }\end{array}$ & $\begin{aligned} \text { NDVI } & =\left(\rho_{\text {nir }}-\rho_{\text {red }}\right) / \\
& \left(\rho_{\text {nir }}+\rho_{\text {red }}\right)\end{aligned}$ & $\begin{array}{l}\text { estimates the amount of vegetation, it } \\
\text { assumes values that are normalized for } \\
\text { the amount of incident radiation }\end{array}$ & Rouse et al. (1974) \\
\hline $\begin{array}{l}\text { Corrected normalized } \\
\text { difference vegetation } \\
\text { index (NDVIC) }\end{array}$ & $\begin{aligned} \text { NDVIC } & =\text { NDVI }\left(1-\left(\left(\rho_{\operatorname{mir}}\right.\right.\right. \\
& \left.-\rho_{\operatorname{mir} \min }\right) /\left(\rho_{\operatorname{mir} \max }\right. \\
& \left.-\rho_{\operatorname{mir} \min }\right)\end{aligned}$ & $\begin{array}{l}\text { linearizes the relationships with } \\
\text { parameters, accounting for MIR band }\end{array}$ & $\begin{array}{l}\text { Nemani et al. } \\
\text { (1993) }\end{array}$ \\
\hline $\begin{array}{l}\text { Modified simple } \\
\text { ratio (MSR) }\end{array}$ & $\begin{array}{l}\operatorname{MSR}=\left(\rho_{\text {nir }} / \rho_{\text {red }}-1\right) /\left(\left(\rho_{\text {nir }} /\right.\right. \\
\left.\left.\rho_{\text {red }}\right)^{1 / 2}+1\right)\end{array}$ & $\begin{array}{l}\text { linearizes the relationship between the } \\
\text { index and biophysical parameters }\end{array}$ & Chen (1996) \\
\hline Reflectance ratio (RR) & $\mathrm{RR}=\rho_{\text {mir }} / \rho_{\text {red }}$ & $\begin{array}{l}\text { substitutes NIR band in SR with MIR } \\
\text { band, which is more sensitive in } \\
\text { distinguishing complex and stratified } \\
\text { forest structures }\end{array}$ & $\begin{array}{l}\text { Tonolli et al. } \\
\text { (2011) }\end{array}$ \\
\hline $\begin{array}{l}\text { Normalized difference } \\
\text { water index (NDWI) }\end{array}$ & $\begin{aligned} \text { NDWI } & =\left(\rho_{\text {nir }}-\rho_{\text {mir }}\right) / \\
& \left(\rho_{\text {nir }}+\rho_{\text {mir }}\right)\end{aligned}$ & sensitive to vegetation water & $\begin{array}{l}\text { Hardinsky et al. } \\
\text { (1983) }\end{array}$ \\
\hline $\begin{array}{l}\text { Specific leaf area } \\
\text { vegetation index } \\
\text { (SLAVI) }\end{array}$ & $\operatorname{SLAVI}=\rho_{\text {nir }} /\left(\rho_{\text {red }}+\rho_{\text {mir }}\right)$ & estimates specific leaf area & $\begin{array}{l}\text { Lymburner et al. } \\
\quad(2000)\end{array}$ \\
\hline Red green ratio (RGR) & $\mathrm{RGR}=\rho_{\text {red }} / \rho_{\text {green }}$ & sensitive to different foliar pigments & $\begin{array}{l}\text { Gamon and } \\
\text { Surfus (1999) }\end{array}$ \\
\hline Red green index (RGI) & $\begin{aligned} \text { RGI } & =\left(\rho_{\text {green }}-\rho_{\text {red }}\right) / \\
& \left(\rho_{\text {green }}+\rho_{\text {red }}\right)\end{aligned}$ & normalization of RGR results & Coops et al. (2006) \\
\hline $\begin{array}{l}\text { Green normalized } \\
\text { difference vegetation } \\
\text { index (GNDVI) }\end{array}$ & $\begin{aligned} \text { GNDVI } & =\left(\rho_{\text {nir }}-\rho_{\text {green }}\right) / \\
& \left(\rho_{\text {nir }}+\rho_{\text {green }}\right)\end{aligned}$ & $\begin{array}{l}\text { estimates the amount of green vegetation, } \\
\text { exploiting the green channel, sensitive to } \\
\text { chlorophyll }\end{array}$ & $\begin{array}{l}\text { Gitelson et al. } \\
\text { (1996) }\end{array}$ \\
\hline $\begin{array}{l}\text { Normalized canopy } \\
\text { index (NCI) }\end{array}$ & $\begin{array}{c}\mathrm{NCI}=\left(\rho_{\text {mir }}-\rho_{\text {green }}\right) / \\
\left(\rho_{\text {mir }}+\rho_{\text {green }}\right)\end{array}$ & $\begin{array}{l}\text { linearizes the relationships with } \\
\text { parameters, accounting for MIR and } \\
\text { green bands }\end{array}$ & $\begin{array}{l}\text { Vescovo and } \\
\text { Gianelle (2008) }\end{array}$ \\
\hline Tasseled cap angle (TCA) & $\mathrm{TCA}=\arctan (\mathrm{TCG} / \mathrm{TCB})$ & $\begin{array}{l}\text { index based on the angle formed by } \\
\text { brightness (TCB) and greenness (TCG) } \\
\text { in the vegetation plane, calculated from } \\
\text { TCT (tasseled cap transformation) }\end{array}$ & $\begin{array}{l}\text { Powell et al. } \\
\text { (2010) }\end{array}$ \\
\hline
\end{tabular}

Notes: NIR, near-infrared; MIR, mid-infrared. 
Model building. - To relate field-sampled values of basal area to the metrics calculated from the Landsat images, we used all newly sampled plots, plus a subsample of the TEAM and Barelli et al. (2015) plots. The subsample plots were those showing at least $75 \%$ overlap with Landsat pixels $(N=115)$. In each plot, we calculated the basal area $\left(\mathrm{BA}, \mathrm{m}^{2}\right)$ for each sampled tree $(\mathrm{DBH} \geq 10 \mathrm{~cm})$ as $\mathrm{BA}=\pi \times(\mathrm{DBH} / 2)^{2}$. We then derived the mean basal area (MBA) for each plot, for use as the response variable (following Barelli et al. [2015] and Cavada et al. [2016]).

We used generalized linear modeling (GLM) to investigate the relationship between the MBA field-sampled values and the Landsat metrics and indices. Prior to building the models, we checked for the presence of collinearity among predictor variables to remove those providing identical information. We thus calculated variance inflation factor (VIF), using a cut off value of 10 (Marquardt 1970, Hair et al. 2006, Kennedy 2008) and we retained the uncorrelated predictors P1 (first component of the principal component analysis), P2 (second component of the principal component analysis), RGI (red green index), RR (red ratio), and SLAVI (specific leaf area vegetation index). From an empirical cumulative distribution function (ECDF) of the response variable, we decided to use an inverse Gaussian error distribution for the GLM with an inverse squared link function (Fig. 2).

We built models using all the possible combinations of the retained Landsat predictors and we used the Akaike information criterion (AIC) to rank the candidate models. We considered those models showing $\triangle \mathrm{AIC}<2$ as equivalent (Anderson and Burnham 2002) and defined an average model by determining Akaike weights $\left(w_{i}\right)$ for each of the best models, using the packages AICcmodavg (Mazerolle 2015) and MUMin (Barton 2014) in R version

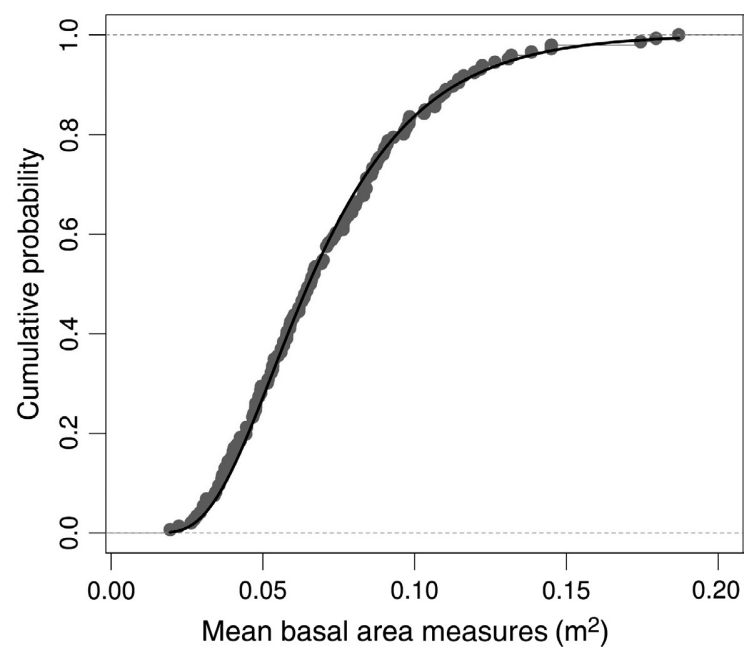

FIG. 2. Empirical cumulative distribution function of ground-sampled measures of mean basal area (MBA, gray dots) collected at tree plots in Mwanihana forest, Udzungwa Mountains, Tanzania. The black line shows the fit of the theoretical inverse Gaussian distribution.
3.2.1 (R Core Team 2015). For validating the model, we randomly split the MBA data set into two subsets, one for model fitting with $75 \%$ of the data $(N=109)$ and one with the remaining $25 \%$ of the data $(N=37)$. We then used bootstrapping to verify the goodness of fit of the selected average model: We simulated 1,000 data sets from the subset derived for model fitting (i.e., the one considering $75 \%$ of the data) and then defined a function that returned the fit-statistic Pearson $\chi^{2}$. We validated the model by checking the distribution of the residuals for the validation subset. We evaluated model bias by comparing both observed and predicted values, to a null model of mean residual prediction equal to zero, using Wilcoxon's signed rank test (for $\alpha=0.05$ ).

Predictions: $M B A$ values and $R C$ density.-To predict density values for groups of red colobus across the entire Mwanihana forest, we first derived spatially diffused values for MBA from our best fitting averaged model, giving an MBA value for each Landsat pixel in the entire study area. We removed those values of MBA that appeared as outliers in the derived data set (i.e., $>0.5 \mathrm{~m}^{2}$ ). We believed these outliers were found for those pixels where our model was not able to derive realistic MBA values, inside those areas close to forest borders as well as in areas located at high elevation (above 1,800 m), where trees are sparse and are replaced by other vegetation (Lovett et al. 2006).

Besides MBA, previous modeling of red colobus group density was most effective using elevation (negative sign, i.e. density decreased with increasing elevation) and distance from disturbance/forest edge (negative sign; Cavada et al. 2016). We therefore calculated spatially diffused values for these variables from a digital elevation model (DEM) and from a shapefile of the forest edge, respectively. We then used a published hierarchical model (Cavada et al. 2016) to predict primate density across the Mwanihana forest using these two variables and spatially diffused values for MBA derived from our model.

Finally, we verified the accuracy of our approach by comparing the predicted primate density to density estimates in Cavada et al. (2016) for those plots in Barelli et al. $(2015 ; N=65)$ that were excluded while building the MBA model (see Model building above). These density estimates were plot-specific values derived from the hierarchical analysis described above, and hence were effectively the only field based and site-specific density estimates that could be used for such validation. We compared observed and predicted values using OP regression (Piñeiro et al. 2008) and we compared the slope and the intercept of the fitted model with the 1:1 line.

\section{Results}

After selecting the plots suitable for the analysis, we retained 61 plots from Barelli et al. (2015) and 54 TEAM sub-plots. Adding these to the 33 newly sampled plots, we obtained an overall data set of 148 plots and their corresponding sampled MBA values. We built models using 
TABLE 2. Akaike information criterion (AIC) value for highranked models $(\triangle \mathrm{AIC}<2)$ of mean basal area $(\mathrm{MBA})$ modeled as a function of predictors derived from a Landsat 8 image.

\begin{tabular}{lll}
\hline \hline Model & AIC & $\Delta$ AIC \\
\hline MBA $\sim$ P1 + RGI & -620.70 & 0 \\
MBA $\sim$ P1 + RGI + RR & -619.89 & 0.81 \\
MBA $\sim$ P1 + SLAVI & -619.46 & 1.24 \\
MBA $\sim$ P1 & -619.097 & 1.607 \\
MBA $\sim$ P1 + P2 + RGI & -619.096 & 1.609 \\
MBA $\sim$ P1 + RR + SLAVI & -618.98 & 1.72 \\
\hline
\end{tabular}

Note: P1, first component of the principal component analysis; $\mathrm{P} 2$, second component of the principal component analysis; RGI, red green index; RR, red ratio; SLAVI, specific leaf area vegetation index.

TABLE 3. Estimates and standard errors for the parameters retained in the averaged model for mean basal area (MBA) modeled as a function of metrics and indices extracted from a Landsat 8 image.

\begin{tabular}{lrcc}
\hline \hline Model-averaged coefficients & Estimate & SE & $P$ \\
\hline P1 & -37.92 & 19.61 & 0.05 \\
RGI & 31.71 & 15.43 & 0.04 \\
RR & 19.40 & 16.45 & 0.2 \\
SLAVI & 27.09 & 16.18 & 0.09 \\
P2 & 18.15 & 24.64 & 0.4 \\
\hline
\end{tabular}

Note: P1, first component of the principal component analysis; $\mathrm{P} 2$, second component of the principal component analysis; RGI, red green index; RR, red ratio; SLAVI, specific leaf area vegetation index.

all the possible combinations of the metrics and indices calculated from the Landsat images, including a null model. We retained six competing models of MBA (Table 2) that were averaged for predictions. The resulting average model retained the first and the second components of the PCA and the indices RGI, RR, and SLAVI (Table 3). This model showed adequate fit based on the bootstrap $P$ value based on the chi-square statistic $(P=0.66)$ and no significant difference between observed and predicted MBA values $(W=602, P=0.92)$. The MBA model failed to derive plausible values in those areas located at high altitudes as well as close to the forest edge (Fig. 3). We obtained a spatially explicit map of estimated density of red colobus groups across the whole study area, as influenced by the covariates MBA (predicted from our model and with a positive effect), elevation and distance from disturbance (i.e., from the forest edge), both with a negative effect, according to the hierarchical model defined in Cavada et al. (2016) (Fig. 4).

The OP regression yielded a $R^{2}$ of 0.84 attesting the accuracy of the predicted red colobus group density values as derived by using the spatially diffused values for MBA obtained from the GLM analysis (Fig. 5).

\section{DisCUSSION}

We have successfully predicted and mapped the spatial density of an endangered primate, hence showing how

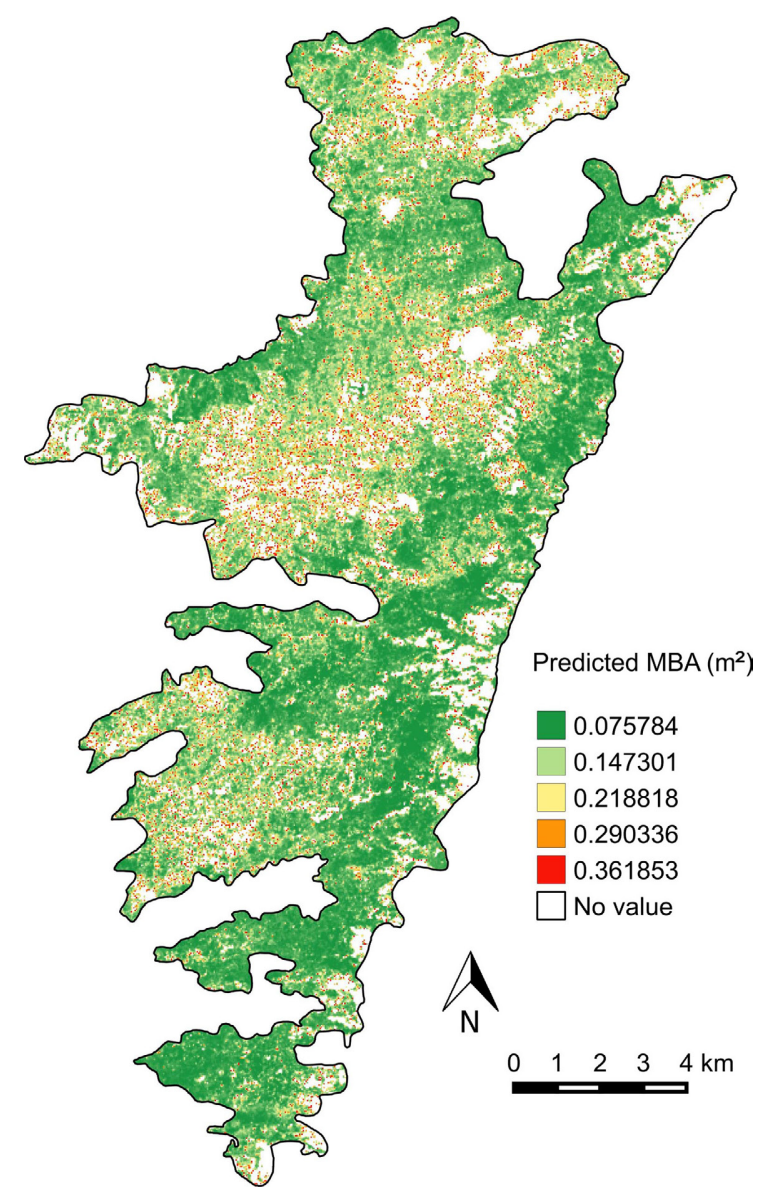

FIG. 3. Predicted values of mean basal area (MBA) across Mwanihana forest using the average model of ground-sampled values vs. Landsat 8 metrics. White areas show pixels where the model failed to predict plausible values of MBA (i.e., $<0.5 \mathrm{~m}^{2}$ ). (Color figure can be viewed at wileyonlinelibrary.com.)

modeling ecologically relevant predictors of abundance can improve predictions on species distribution (Franklin 1995), across a broad spatial extent. The species' density pattern highlighted in our map is consistent with results in previous studies that were based solely on ground data and hence with limited spatial inference (Struhsaker and Rovero 2007, Barelli et al. 2015, Cavada et al. 2016).

Our best supported models showed high accuracy in predicting MBA values, making it a reliable tool for inference beyond the ground measurement sites, with a good level of confidence and precision. MBA is a highly relevant descriptor of the canopy structure as well as a significant covariate that has emerged in different studies as influential for predominantly arboreal primates (Struhsaker and Rovero 2007, Cavada et al. 2016). As a parameter quantifying forest cover, MBA is also a recognized proxy for habitat degradation and fragmentation (Urquiza-Haas et al. 2007). The best-fit model we derived from GLM retained the first two components of the PCA. This fit the acknowledged evidence that Landsat products 


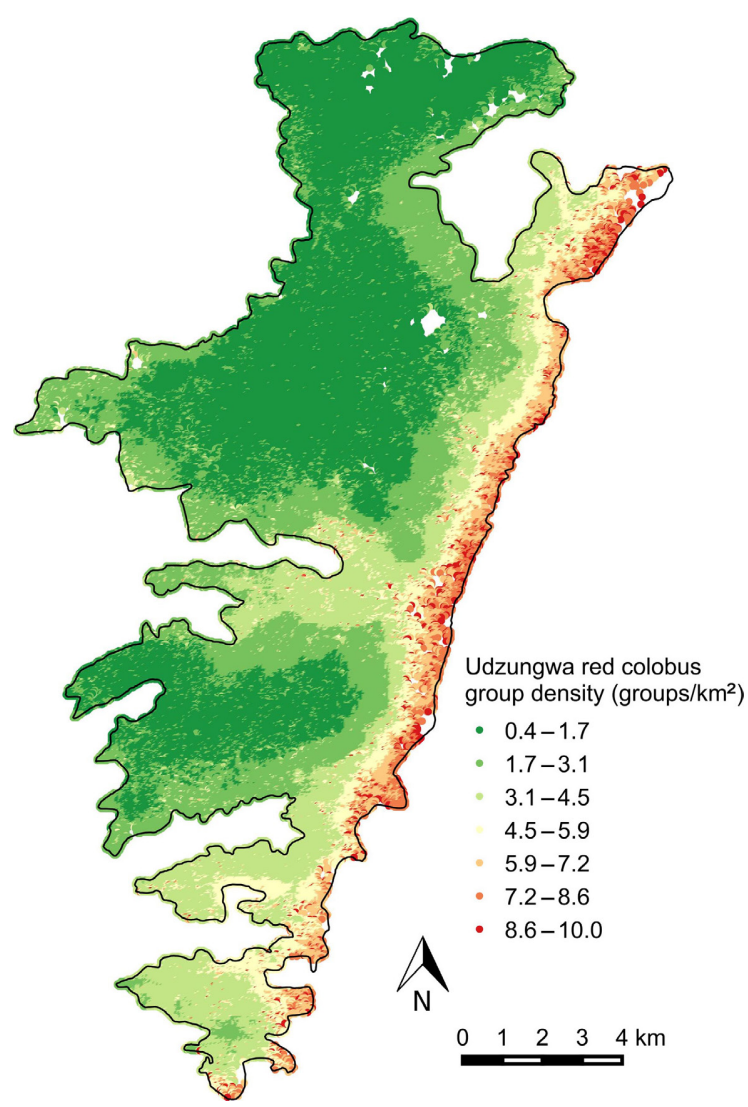

FIG. 4. Predicted Udzungwa red colobus group density in Mwanihana forest using a species density model (Cavada et al. 2016) derived from remotely sensed mean basal area. (Color figure can be viewed at wileyonlinelibrary.com.)

are able to discriminate forested habitats, through the information provided by specific spectral channels (Blair and Baumgardner 1977, Jakubauskas 1996, Eklundh et al. 2001, Cohen and Goward 2004), in terms of the differential reflectance emitted by the higher strata of the canopy. The information provided by the Landsat sensors can highlight specific vegetation components (Thenkabail et al. 2000, Almeida and De Souza Filo 2004); in fact the bands of the visible spectrum and of the short-wave infrared (SWIR) can be correlated with several forest structures, including basal area (Muukkonen and Heiskanen 2005, 2007, Hall et al. 2006). The relationship with MBA shown by the first PCA component of our model might be due to a large presence of trees with great basal area and tall canopy, causing pronounced shadowing, which translates in a lower reflectance.

Among the vegetation indices retained by the models, RGI can be interpreted as a proxy of the forest phenology at the time when the Landsat image was acquired. Since such an index provides information on the ratio of red to green reflectance, the positive effect we found on MBA could be due to the contribution the index generally gives in evaluating the size of the tree crowns, which is related to the basal area extent. During that period, a high number of trees did show a breakdown of green pigments and leaves fading from green to yellow and red (Motohka et al. 2010). The positive effect we found for RR was also confirmed by other studies that found a correlation between the visible and the SWIR band of the Landsat with several physical structures of the forest canopy, including basal area (Muukkonen and Heiskanen 2005, Hall et al. 2006, Tonolli et al. 2011). In addition, the positive relationship we found between MBA and SLAVI index is not surprising given that the index accounts for the sensitivity of the mid-infrared wavelength to the structure of the canopy, especially for heterogeneous forest compositions (Lymburner et al. 2000).

As the main goal of our study, we used the predicted and spatially diffused values of MBA to derive a map of the Udzungwa red colobus density. This matched, at a wider and spatially diffuse scale, the density estimates found in prior studies (Barelli et al. 2015, Cavada et al. 2016). In particular, it confirmed the red colobus's preference for lower-elevation forest close to its edge, variably disturbed and covered with regenerating vegetation, that is recognized as an important food source for the species (Barelli et al. 2015). Densities decreased where MBA values increased, i.e., in the interior and old growth forest and at higher elevation. This, in turn, indicates resilience of the animal to anthropogenic disturbance and again the preference shown by the species for forest edges. Such a counterintuitive density trend is clearly visualized in the spatially explicit map we obtained. This provides novel indications for the protection of forest areas that are located at the interface with intense anthropogenic activity.

We have confirmed that the use of remote sensing represents a robust tool to improve model performance and to reduce the costs of data collection (He et al. 2015),

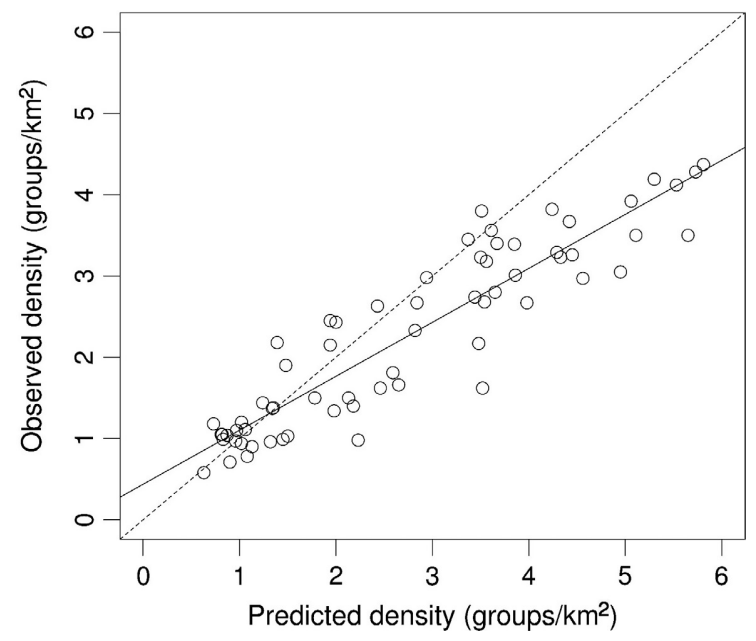

FIG. 5. Linear regression (dotted line) of observed vs. predicted values of Udzungwa red colobus density (groups $/ \mathrm{km}^{2}$ ) among test vegetation plots $(N=66)$. A 1:1 relationship is indicated by the solid line. Observations are from Cavada et al. (2016). 
which implies bypassing the sample size limits associated with field measurements. We stress the importance of carefully evaluating the process regarding the selection of adequate satellite images, given the sensitivity for seasonality shown by some vegetation indices. High resolution images should certainly be preferred when deriving remote-sensing based predictor variables that can be essential to improve predictive species modeling. Nonetheless, the quality of such images can often be poor, due to cloud coverage that hides the underlying canopy, i.e., the carried amount of information is lower than the spectral noise (Woodcock and Strahler 1987, Ricotta et al. 1999). This phenomenon consistently arises in images of tropical mountain forests, since clouds accumulate relatively more in dense forest cover areas due to evapotranspiration (Nagendra and Rocchini 2008). Still, we demonstrated that since high resolution products in some cases cannot be used, medium resolution images like Landsat proved to be an excellent source of data for applications both in the study of tropical forest structure and to develop reliable species distribution models. However, caution is recommended regarding the generalization of our approach, which is mainly relevant to comparable study systems in terms of both habitat and target species characteristics.

\section{Conclusions}

Spatially explicit, predictive models of animal abundance can offer a powerful insight on the species status and distribution, helping to identify those sites where urgent intervention is needed in terms of protection and conservation. Overcoming the lack of high resolution and high quality remote-sensing products as well as of spatially diffused covariates of abundance is essential, as it can firmly boost the usefulness of species distribution models. By focusing on the endangered Udzungwa red colobus, we showed the potential of this approach to derive accurate spatially diffused estimates of animal density and distribution. This approach is particularly suitable for species for which data availability is incomplete and spatial coverage is heterogeneous, affecting the capacity of developing site-specific conservation and restoration programs where urgent forest and species protection is needed.

\section{ACKNOWLEDGMENTS}

We thank the Tanzania Wildlife Research Institute (TAWIRI), Tanzania Commission for Science and Technology (COSTECH), Tanzania National Parks (TANAPA), and the Tanzania Forest Service (TFS) for granting us permissions to collect the new data for the study (Costech Permit No. 201544- NA-2015- 37 to N. Cavada). The new data collection for this study was funded by Rufford Small Grants Foundation (1106-C to F. Rovero), and by MUSE-Museo delle Scienze and the University of Trento to N. Cavada. We thank L. Perathoner for providing helpful support and valuable suggestion for the analysis of the Landsat data set and for the implementation of the GRASS code. R. Laizzer and A. Mwakisoma provided invaluable field assistance. We thank the Tropical Ecology Assessment and Monitoring (TEAM) Network, a collaboration among Conservation International, the Smithsonian Institute, and the Wildlife Conservation Society, for providing part of the tree plot data set; some of these plots were in turn established through the Valuing the Arc program and in collaboration with J. Lovett, S. Lewis, and P. Munishi. We thank H. Little for proofreading the final version of the manuscript and two anonymous reviewers for their relevant suggestions through the revision process.

\section{Literature Cited}

Alexander, R. R. 1971.Crown competition factor (CCF) for Engelmann spruce in the Central Rocky Mountains. Forest Service, U.S. Department of Agriculture, Rocky Mountain Forest and Range Experiment Station, Fort Collins, Colorado.

Almeida, T. I. R., and C. De Souza Filo. 2004. Principal component analysis applied to feature-oriented band ratios of hyperspectral data: a tool for vegetation studies. International Journal of Remote Sensing 25:5005-5023.

Anadón, J. D., A. Giménez, and R. Ballestar. 2010. Linking local ecological knowledge and habitat modelling to predict absolute species abundance on large scales. Biodiversity and Conservation 19:1443-1454.

Anderson, D. R., and K. P. Burnham. 2002. Avoiding pitfalls when using information-theoretic methods. Journal of Wildlife Management 66:912-918.

Anderson, J., G. Cowlishaw, and J. M. Rowcliffe. 2007. Effects of forest fragmentation on the abundance of Colobus angolensis palliatus in Kenya's coastal forests. International Journal of Primatology 28:637-655.

Araldi, A., C. Barelli, K. Hodges, and F. Rovero. 2014. Density estimation of the endangered Udzungwa red colobus (Procolobus gordonorum) and other arboreal primates in the Udzungwa Mountains using systematic distance sampling. International Journal of Primatology 35:941-956.

Arroyo-Rodríguez, V., and L. Fahrig. 2014. Why is a landscape perspective important in studies of primates? American Journal of Primatology 909:901-909.

Balmford, A., and T. Whitten. 2003. Who should pay for tropical conservation, and how could the costs be met? Oryx 37:238-250.

Barelli, C., R. Mundry, A. Araldi, K. Hodges, D. Rocchini, and F. Rovero. 2015. Modelling primate abundance in complex landscapes: a case study from the Udzungwa Mountains of Tanzania. International Journal of Primatology 36:209-226.

Barton, K. 2014. Multi-model inference. R package MuMIn version 1.10.5, 46. https://cran.r-project.org/web/packages/ MuMIn/index.html

Blair, B. O., and M. F. Baumgardner. 1977. Detection of the green and brown wave in hardwood canopy covers using multidate, multispectral data from LANDSAT-1. Agronomy Journal 69:808-811.

Braithwaite, L. W., M. P. Austin, M. Clayton, J. Turner, and A. O. Nicholls. 1989. On predicting the presence of birds in Eucalyptus forest types. Biological Conservation 50:33-50.

Brown, L., J. M. Chen, S. G. Leblanc, and J. Cihlar. 2000. A shortwave infrared modification to the simple ratio for LAI retrieval in boreal forests: an image and model analysis. Remote Sensing of Environment 71:16-25.

Cade, B. S. 1997. Comparison of tree basal area and canopy cover in habitat models: subalpine forest. Journal of Wildlife Management 61:326-335.

Cavada, N., C. Barelli, M. Ciolli, and F. Rovero. 2016. Primates in human-modified and fragmented landscapes: the 
conservation relevance of modelling habitat and disturbance factors in density estimation. PLoS ONE 11:e0148289.

Cayuela, L., D. Golicher, A. Newton, H. Kolb, F. S. de Alburquerque, E. J. M. M. Arets, J. R. M. Alkemade, and A. M. Pérez. 2009. Species distribution modelling in the tropics: problems, potentialities, and the role of biological data for effective species conservation. Tropical Conservation Science 2:319-352.

Chen, J. M. 1996. Evaluation of vegetation indices and a modified simple ratio for boreal applications. Canadian Journal of Remote Sensing 22:1-21.

Cohen, W. B., and S. N. Goward. 2004. Landsat's role in ecological applications of remote sensing. BioScience 54: $535-545$.

Cohen, W. B., T. A. Spies, and M. Fiorella. 1995. Estimating the age and structure of forests in a multi-ownership landscape of western Oregon, U.S.A. International Journal of Remote Sensing 16:721-746.

Coops, N. C., M. Johnson, M. A. Wulder, and J. C. White. 2006. Assessment of QuickBird high spatial resolution imagery to detect red attack damage due to mountain pine beetle infestation. Remote Sensing of Environment 103: 67-80.

Cristóbal-Azkarate, J., J. J. Veà, N. Asensio, and E. RodríguezLuna. 2005. Biogeographical and floristic predictors of the presence and abundance of mantled howlers (Alouatta palliata mexicana) in rainforest fragments at Los Tuxtlas, Mexico. American Journal of Primatology 67: 209-222.

Duncanson, L. I., K. O. Niemann, and M. A. Wulder. 2010. Integration of GLAS and Landsat TM data for aboveground biomass estimation. Canadian Journal of Remote Sensing 36:129-141.

Eklundh, L., L. Harrie, and A. Kuusk. 2001. Investigating relationships between Landsat ETM+ sensor data and leaf area index in a boreal conifer forest. Remote Sensing of Environment 78:239-251.

Farr, W. A., D. J. DeMars, and J. E. Dealy. 1989. Height and crown width related to diameter for open-grown western hemlock and Sitka spruce. Canadian Journal of Forest Research 19:1203-1207.

Franklin, J. 1995. Predictive vegetation mapping: geographic modelling of biospatial patterns in relation to environmental gradients. Progress in Physical Geography 19:474-499.

Gamon, J. A., and J. S. Surfus. 1999. Assessing leaf pigment content and activity with a reflectometer. New Phytologist 143:105-117.

Gitelson, A. A., Y. J. Kaufman, and M. N. Merzlyak. 1996. Use of a green channel in remote sensing of global vegetation from EOS-MODIS. Remote Sensing of Environment 58: 289-298.

Guisan, A., and W. Thuiller. 2005. Predicting species distribution: offering more than simple habitat models. Ecology Letters 8:993-1009.

Guisan, A., and N. E. Zimmermann. 2000. Predictive habitat distribution models in ecology. Ecological Modelling 135: $147-186$.

Hair, J. F., B. Black, B. Babin, R. E. Anderson, and R. L. Tatham. 2006. Multivariate data analysis. Sixth edition. Prentice Hall, Cornell University, New York.

Hall, F. G., Y. E. Shimabukuro, and K. Huemmrich. 1995. Remote sensing of forest biophysical structure using mixture decomposition and geometric reflectance models. Ecological Applications 5:993-1013.

Hall, R. J., R. S. Skakun, E. J. Arsenault, and B. S. Case. 2006. Modelling forest stand structure attributes using Landsat ETM+ data: application to mapping of aboveground biomass and stand volume. Forest Ecology and Management 225:378-390.

Hardinsky, M. A., V. Klemas, and R. M. Smart. 1983. The influence of soil salinity, growth form and leaf moisture on the spectral radiance of Spartina alterniflora canopies. Photogrammetric Engineering and Remote Sensing 48:77-84.

He, K. S., B. A. Bradley, A. F. Cord, D. Rocchini, M. N. Tuanmu, S. Schmidtlein, W. Turner, M. Wegmann, and N. Pettorelli. 2015. Will remote sensing shape the next generation of species distribution models? Remote Sensing in Ecology and Conservation 1:4-18.

IUCN. 2015. The IUCN Red List of Threatened Species. Version 2015-4. www.iucnredlist.org

Jackson, R. D., and A. R. Huete. 1991. Interpreting vegetation indices. Preventive Veterinary Medicine 11:185-200.

Jakubauskas, M. E. 1996. Thematic mapper characterization of lodgepole pine seral stages in Yellowstone National Park, USA. Remote Sensing of Environment 56:118-132.

Jordan, C. F. 1969. Derivation of leaf-area index from quality of light on the forest floor. Ecology 50:663-666.

Kennedy, P. 2008. A guide to econometrics. Sixth edition. Wiley-Blackwell, Oxford.

Legaard, K. R., S. A. Sader, and E. M. Simons-Legaard. 2015. Evaluating the impact of abrupt changes in forest policy and management practices on landscape dynamics: analysis of a Landsat image time series in the Atlantic Northern Forest. PLoS ONE 10:e0130428.

Lovett, J. C., A. R. Marshall, and J. Carr. 2006. Changes in tropical forest vegetation along an altitudinal gradient in the Udzungwa Mountains National Park, Tanzania. African Journal of Ecology 44:478-490.

Lymburner, L., P. Beggs, and C. Jacobson. 2000. Estimation of canopy-average surface-specific leaf area using Landsat TM data. Photogrammetric Engineering and Remote Sensing 66:183-191.

Marquardt, D. W. 1970. Generalized inverses, ridge regression, biased linear estimation, and nonlinear estimation. Technometrics 12:591-612.

Marshall, A. R., H. I. O. Jørgensbye, F. Rovero, P. J. Platts, P. C. L. White, and J. C. Lovett. 2010. The species-area relationship and confounding variables in a threatened monkey community. American Journal of Primatology 72:325-336.

Marshall, A. R., et al. 2012. Measuring and modelling aboveground carbon and tree allometry along a tropical elevation gradient. Biological Conservation 154:20-33.

Mayes, M. T., J. F. Mustard, and J. M. Melillo. 2015. Forest cover change in Miombo Woodlands: modelling land cover of African dry tropical forests with linear spectral mixture analysis. Remote Sensing of Environment 165:203-215.

Mazerolle, M. J. 2015. R package AICcmodavg. Model selection and multimodel inference based on (Q)AIC(c). https:// cran.r-project.org/web/packages/AICcmodavg/index.html

Mbora, D. N. M., and D. B. Meikle. 2004. Forest fragmentation and the distribution, abundance and conservation of the Tana river red colobus (Procolobus rufomitratus). Biological Conservation 118:67-77.

Medley, K. E. 1993. Primate conservation along the Tana River, Kenya: an examination of the forest habitat. Conservation Biology 7:109-121.

Motohka, T., K. N. Nasahara, H. Oguma, and S. Tsuchida. 2010. Applicability of green-red vegetation index for remote sensing of vegetation phenology. Remote Sensing 2: 2369-2387.

Muukkonen, P., and J. Heiskanen. 2005. Estimating biomass for boreal forests using ASTER satellite data combined with standwise forest inventory data. Remote Sensing of Environment 99:434-447. 
Muukkonen, P., and J. Heiskanen. 2007. Biomass estimation over a large area based on standwise forest inventory data and ASTER and MODIS satellite data: a possibility to verify carbon inventories. Remote Sensing of Environment 107: $617-624$.

Nagendra, H., and D. Rocchini. 2008. High resolution satellite imagery for tropical biodiversity studies: the devil is in the detail. Biodiversity and Conservation 17:3431-3442.

Nemani, R., L. Pierce, S. Running, and L. Band. 1993. Forest ecosystem processes at the watershed scale: sensitivity to remotely-sensed leaf area index estimates. International Journal of Remote Sensing 14:2519-2534.

Neteler, M., M. Hamish Bowman, M. Landa, and M. Metz. 2012. GRASS GIS: a multi-purpose open source GIS. Environmental Modelling \& Software 31:124-130.

Piñeiro, G., S. Perelman, J. P. Guerschman, and J. M. Paruelo. 2008. How to evaluate models: Observed vs. predicted or predicted vs. observed? Ecological Modelling 216:316-322.

Platts, P. J., N. D. Burgess, R. E. Gereau, J. C. Lovett, A. R. Marshall, C. J. Mc Clean, P. K. E. Pellikka, R. D. Swetnam, and R. Marchant. 2011. Delimiting tropical mountain ecoregions for conservation. Environmental Conservation 38:312-324.

Powell, S. L., W. B. Cohen, S. P. Healey, R. E. Kennedy, G. G. Moisen, K. B. Pierce, and J. L. Ohmann. 2010. Quantification of live aboveground forest biomass dynamics with Landsat time-series and field inventory data: a comparison of empirical modelling approaches. Remote Sensing of Environment 114:1053-1068.

Proisy, C., P. Couteron, and F. Fromard. 2007. Predicting and mapping mangrove biomass from canopy grain analysis using Fourier-based textural ordination of IKONOS images. Remote Sensing of Environment 109:379-392.

R Core Team. 2015. R: a language and environment for statistical computing. R Foundation for Statistical Computing, Vienna, Austria. https://www.R-project.org/

Ricotta, C., G. C. Avena, and F. Volpe. 1999. The influence of principal component analysis on the spatial structure of a multispectral dataset. International Journal of Remote Sensing 20:3367-3376.

Rouse, J. W., R. H. Haas, J. A. Schell, W. D. Deering, and J. C. Harlan. 1974. Monitoring the vernal advancement and retrogradation (greenwave effect) of natural vegetation. Technical report. National Aeronautics and Space Administration, Washington, D.C., USA.

Schipper, J., et al. 2008. The status of the world's land and marine mammals: diversity, threat, and knowledge. Science 322:225-230.

Schroeder, T. A., M. A. Wulder, S. P. Healey, and G. G. Moisen. 2011. Mapping wildfire and clearcut harvest disturbances in boreal forests with Landsat time series data. Remote Sensing of Environment 115:1421-1433.
Schwitzer C., R. A. Mittermeier, A. B. Rylands, F. Chiozza, E. A. Williamson, J. Wallis, and A. Cotton, editors. 2015. Primates in peril: the world's 25 most endangered primates 2014-2016. IUCN SSC Primate Specialist Group (PSG), International Primatological Society (IPS), Conservation International (CI), and Bristol Zoological Society, Arlington, Virginia, USA.

Smith, W. R., R. M. Farrar Jr., P. A. Murphy, J. L. Yeiser, R. S. Meldahl, and J. S. Kush. 1992. Crown and basal area relationships of open-grown southern pines for modelling competition and growth. Canadian Journal of Forest Research 22:341-347.

Struhsaker, T. T., and F. Rovero. 2007. Vegetative predictors of primate abundance: utility and limitations of a fine-scale analysis. American Journal of Primatology 69:1242-1256.

TEAM Network. 2011. Terrestrial vertebrate protocol implementation manual, v. 3.1. Tropical Ecology, Assessment and Monitoring Network, Center for Applied Biodiversity Science, Conservation International, Arlington, Virginia, USA.

Thenkabail, P. S., R. B. Smith, and E. De Pauw. 2000. Hyperspectral vegetation indices and their relationships with agricultural crop characteristics. Remote Sensing of Environment 71:158-182.

Tonolli, S., M. Dalponte, M. Neteler, M. Rodeghiero, L. Vescovo, and D. Gianelle. 2011. Fusion of airborne LiDAR and satellite multispectral data for the estimation of timber volume in the Southern Alps. Remote Sensing of Environment 115:2486-2498.

Twongyirwe, R., M. Bithell, K. S. Richards, and W. G. Rees. 2015. Land use policy three decades of forest cover change in Uganda's Northern Albertine Rift Landscape. Land Use Policy 49:236-251.

Umapathy, G., and A. Kumar. 2000. The occurrence of arboreal mammals in the rain forest fragments in the Anamalai Hills, South India. Biological Conservation 92:311-319.

Urquiza-Haas, T., P. M. Dolman, and C. A. Peres. 2007. Regional scale variation in forest structure and biomass in the Yucatan Peninsula, Mexico: effects of forest disturbance. Forest Ecology and Management 247:80-90.

Vescovo, L., and D. Gianelle. 2008. Using the MIR bands in vegetation indices for the estimation of grassland biophysical parameters from satellite remote sensing in the Alps region of Trentino (Italy). Advances in Space Research 41:1764-1772.

Wilkie, D. S., and J. T. Finn. 1996. Remote sensing imagery for natural resources monitoring: a guide for first-time users. Columbia University Press, Chichester, New York.

Woodcock, C. E., and A. H. Strahler. 1987. The factor of scale in remote sensing. Remote Sensing of Environment 21: 311-332.

Wulder, M. A., and S. E. Franklin. 2006. Understanding forest disturbance and spatial pattern, remote sensing and GIS approaches. CRC Press, Boca Raton, FL.

\section{SUPPORTING INFORMATION}

Additional Supporting Information may be found online at: http://onlinelibrary.wiley.com/doi/10.1002/eap.1438/full 